\title{
Pesquisa experimental para avaliar a qualidade da água e a capacidade de retenção de água pluvial em coberturas verdes em Campinas - Brasil
}

Research experimental to evaluate the quality of the water and the capacity of retention of pluvial water in green roofs in Campinas - Brazil

MARCIA BARRETO IBIAPINA, Arq., Faculdade de Engenharia Civil, Arquitetura e Urbanismo, UNICAMP

VANESSA GOMES DA SILVA, Arq. Profa. Dra., Departamento de Arquitetura e Construção, Faculdade de Engenharia Civil, Arquitetura e Urbanismo, UNICAMP

MARINA SANGOI DE OLIVEIRA ILHA, Eng. Profa. Dra., Departamento de Arquitetura e Construção, Faculdade de Engenharia Civil, Arquitetura e Urbanismo, UNICAMP

DORIS C. C. K. KOWALTOWSKI, Arq. Profa. Dra., Departamento de Arquitetura e Construção, Faculdade de Engenharia Civil, Arquitetura e Urbanismo, UNICAMP

Arquiteta e Urbanista, graduada pela Faculdade de Arquitetura e Urbanismo, Universidade Metodista de Piracicaba, mestranda em Gestão e Tecnologia do Ambiente Construído pelo Programa de PósGraduação da Faculdade de Engenharia Civil, Arquitetura e Urbanismo da Universidade Estadual de Campinas

ibiapina@fec.unicamp.br vangomes@fec.unicamp.br milha@fec.unicamp.br doris@fec.unicamp.br

\section{Resumo}

O crescimento urbano das cidades em desenvolvimento em diferentes partes do mundo é dinâmico e desordenado, com a utilização de cada vez mais espaços, propiciando impactos ambientais com enchentes e enxurradas. Isso ocorre devido à escassez de áreas de infiltração, que protegem o solo da ação da água evitando processos erosivos, deslizamentos de terra e consequentemente problemas sociais e danos a vida humana. Uma parcela significativa das áreas impermeáveis corresponde às superfícies das coberturas. Nos últimos dez anos as coberturas verdes vêm sendo amplamente pesquisadas para verificar o seu potencial no desempenho térmico, na retenção de água pluvial, na 
qualidade da água drenada, assim como na recuperação de áreas permeáveis para mitigar os danos causados pelas enchentes. Na Universidade Estadual de Campinas encontra-se em desenvolvimento um experimento que avalia tanto a capacidade de retenção de água pluvial, qualidade da água escoada como o desempenho térmico em coberturas verdes. O presente artigo tem como objetivo apresentar os resultados obtidos para a qualidade da água pluvial escoada em coberturas e o seu potencial para reuso em edifícios. Para analisar a qualidade da água pluvial utilizou-se 09 célulasteste, sendo 04 do tipo extensivo com $0,10 \mathrm{~m}$ de profundidade do substrato (inclinação de $2 \%$ ); 2 do tipo extensivo modular com 0,09m de profundidade do substrato (inclinação de 2\%); 2 do tipo semiintensivo com $0.25 \mathrm{~m}$ de profundidade do substrato (inclinação de $2 \%$ ); 1 célula-teste com cobertura cerâmica (inclinação de 25\%). Para a coleta de dados desenvolveu-se um projeto específico para a análise da retenção e do escoamento da água pluvial. Para cada célula-teste instalou-se um balde eletrônico que registra o escoamento superficial. Após o balde eletrônico foram instalados 5 coletores, onde o primeiro serve para a análise do primeiro jato (first flush). Após os 5 coletores foi instalado um filtro em "Y" e uma caixa d'água de 500 I para armazenar a água escoada. Verificou-se inclusive a qualidade da água após permear o filtro em "Y", tornando possível a análise de um processo simples e econômico de filtragem da água pluvial. As precipitações foram classificadas em leve, moderada e intensa utilizando uma estação meteorológica. Para a avaliação da qualidade da água e o escoamento superficial consideraram-se as propriedades distintas dos substratos utilizados e as geomantas filtrantes.

Palavras-chave: Cobertura verde; Retenção de água pluvial; escoamento; qualidade da água.

\section{Abstract}

Concerns regarding anticipated water supply scenarios have come to the international forefront, while urban centers impermeability and climate change are resulting in more frequent and stronger storm events. Green roof technology has gained attention in the technical community due to its potential multifold contribution in mitigation of urban flooding damage, provision of alternative water source, increase in urban biodiversity and energy savings associated to thermal performance role in both indoor and outdoor environments. An ongoing research project at University of Campinas aims at assessing both thermal comfort and rainwater retention contribution of a set of green roof test cells. From a representative sample of the green roofs systems available in the Brazilian market, nine test cells were assembled as follows: four extensive green roofs cells, substrate thickness of $0.10 \mathrm{~m}$ (with a $2 \%$-slope); two modular extensive green roofs cells with configurations, substrate thickness of $0.09 \mathrm{~m}$ (with a $2 \%$ slope); two semi-intensive cells, with substrate thickness of $0.25 \mathrm{~m}$ (with a $2 \%$-slope); and one reference cell (ceramic tile roof inclined at 25\%). Each test cell received a tipping bucket that registers 


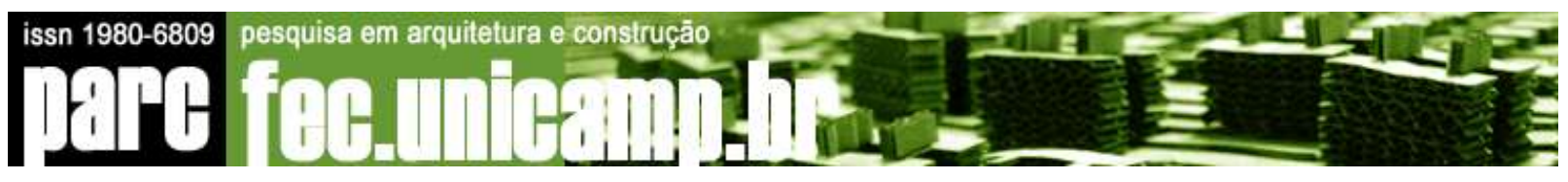

runoff. Sequentially, a set of five rainwater collectors, a "Y" filter and a 310-liter water box for collected rainwater storage were assembled. This paper describes the experimental approach and arrangement proposed to support such evaluations. Unfolding of this research includes validation of test cells format to carry out rainwater studies and comparative analysis to an integral, full-scale, green roof. It is expected to determine the contribution of the studied green roofs to rainwater retention and pretreatment for the region of Campinas, as well as to provide a standardized methodological approach for replication of such studies in other regions.

Keywords: Green roof; vegetated roof; rainwater retention; runoff; water quality 
Pesquisa experimental para avaliar a qualidade da água e a capacidade de retenção de água pluvial em coberturas verdes em campinas - Brasil'

\section{Introdução}

A falta de saneamento básico, o déficit habitacional, o consumo predatório e as próprias causas naturais que afetam a disponibilidade, como as características climáticas e a concentração dos recursos hídricos em regiões de menor densidade populacional tornam o cenário do abastecimento de água atual e futuro bastante preocupante, mesmo em um país como o Brasil, que possui cerca de $12 \%$ da água mundial (AGÊNCIA NACIONAL DE ÁGUAS, 2009).

O crescimento urbano das cidades em desenvolvimento em diferentes partes do mundo é dinâmico e desordenado, com a utilização de cada vez mais espaços, propiciando impactos ambientais com enchentes e enxurradas. Isso ocorre devido à escassez de áreas de infiltração, que protegem o solo da ação da água evitando processos erosivos, deslizamentos de terra e consequentemente problemas sociais e danos à vida humana. A remoção das áreas verdes propicia ainda o desequilíbrio do balanço térmico que reduz a evapotranspiração, dando origens a ilhas de calor (BANTING et al., 2005; U.S. ENVIRONMENTAL PROTECTION AGENCY, 1999). Uma parcela significativa das áreas impermeáveis está associada às coberturas convencionais (CARTER; JACKSON, 2007; GETTER;ROWE; ANDRESEN, 2007).

Esse conjunto de variáveis acrescentadas ao ciclo hidrológico natural dá origem ao chamado ciclo urbano da água. Assim, para que o ciclo da água seja sustentável, uma série de medidas devem ser implementadas no meio urbano, como mostrado na FIG. 1 (WATER BY DESIGN, 2009). 


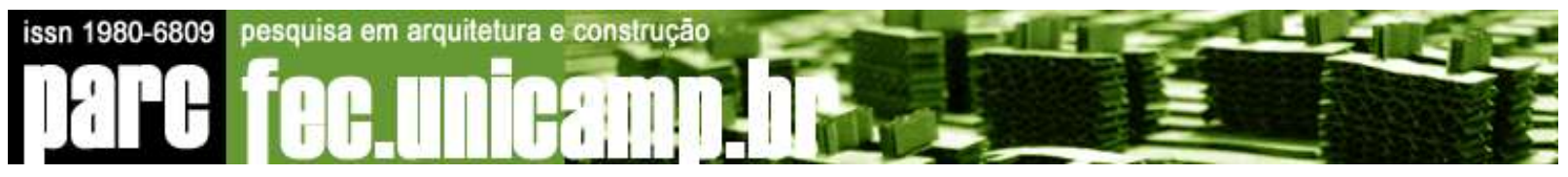

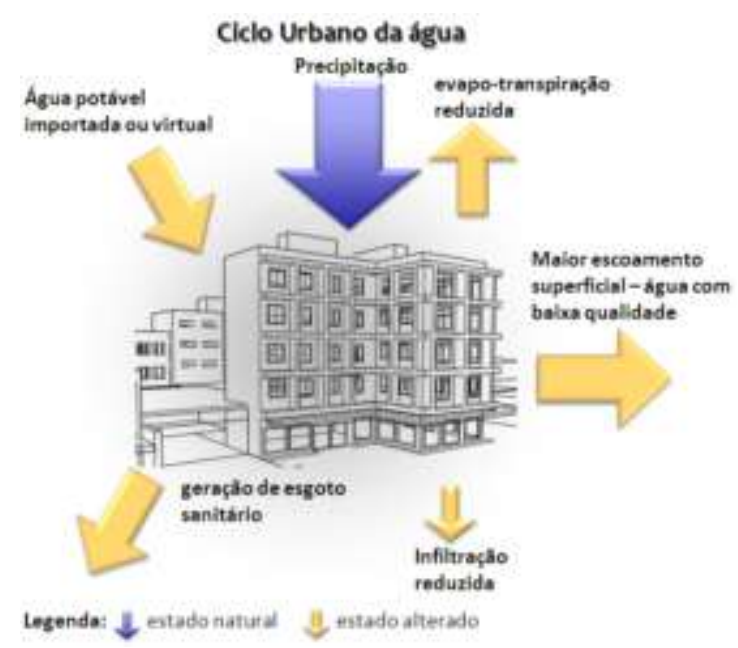

(a)

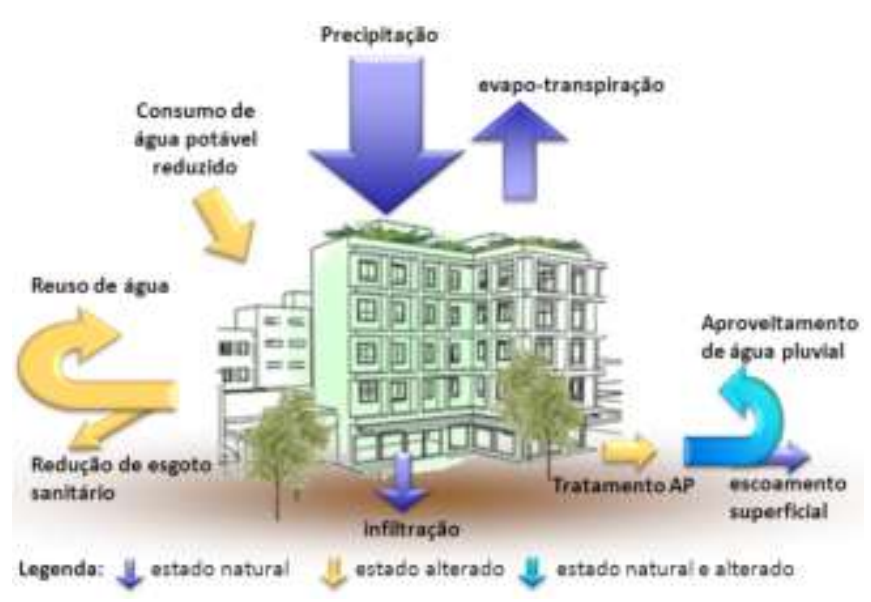

(b)

FIGURA 1 - Ciclo Hidrológico: (a) urbano (b) urbano sustentável.

Fonte: adaptado de Hoban, Wong (2006) apud Water by design (2009).

Alguns estudos conduzidos no país atestam que reduções drásticas do consumo de água potável - e, consequentemente, do esgoto sanitário gerado - podem ser obtidas aliandose sistemas e componentes economizadores à sensibilização dos usuários e a um programa contínuo de monitoramento, a partir da medição setorizada desse insumo. Além disso, o reuso de águas servidas também contribui para o uso de menores volumes de água potável (NUNES, 2000; OLIVEIRA, 2001; SAUTCHUK, 2004).

De sua vez, a detenção, tratamento e retenção da água pluvial com o posterior aproveitamento também contribui para a redução do consumo de água potável, além de se constituir em uma medida não estrutural para o controle de inundações, devido à redução do escoamento superficial. As coberturas verdes, em conjunto com sistemas pontuais de infiltração, vêm sendo amplamente utilizadas como ferramentas eficazes para auxiliar na mitigação dos impactos ambientais que as enchentes causam nos centros urbanos. $O$ potencial da utilização de coberturas verdes para este fim está associado à capacidade de reter grandes quantidades de chuva, podendo, em determinados casos, ser capazes de prolongar a retenção até a próxima chuva (VANWOERT et al., 2005).

As coberturas verdes se classificam em três tipos, de acordo com o uso, metodologia construtiva, os tipos de plantas e a forma de plantio, conforme apresentado na QUADRO 1 (CANTOR, 2008; FORSCHUNGSGESELLSCHAFT LANDSCHAFTSENTWICKLUNG LANDSCHAFTSBAU E.V., 2002). 
Extensivo

Aplicação em coberturas

Profundidade

Variedade de plantas

Peso saturado $\left(\mathrm{Kg} / \mathrm{m}^{2}\right)$

Acessibilidade

Irrigação

Manutenção

Custo

Plana a inclinada
$0.04 \mathrm{~m}$ a $0.20 \mathrm{~m}$
Limitada
48 a $150 \mathrm{~kg} / \mathrm{m}^{2}$
Não acessível
Mínima
Mínima
Baixo

Plana a inclinada

Semi-intensivo intensivo simples

Plana

$0.12 \mathrm{~m}$ a $1.00 \mathrm{~m}$

Diversificada

120 a $200 \mathrm{~kg} / \mathrm{m}^{2}$

Parcialmente acessível

Média a elevada

Média a elevada

Média a elevada ou Intensivo

\section{Plana}

$0.15 \mathrm{~m}$ a $2.00 \mathrm{~m}$

Diversificada

200 a 1.500 kg/m²

Acessível

Igual a qualquer jardim

Elevada

Elevado

QUADRO 1 - Características básicas de uma cobertura verde de acordo com a sua classificação.

Fonte: adaptado de Cantor (2008) e FLL e.V (2002).

Segundo Carter e Jackson (2007), a contribuição de uma cobertura verde na retenção da água pluvial ocorre logo na fase inicial da precipitação e depende da saturação do substrato durante o evento. Estima-se que possa ocorrer uma redução de até $30 \%$ da vazão de água pluvial no sistema de drenagem urbana. Além disso, segundo Berndtsson et al. (2006), esses sistemas podem contribuir na redução da poluição da água pluvial causada pela drenagem urbana durante as enchentes, absorvendo poluentes depositados nas superfícies e na atmosfera, contribuindo diretamente na remediação hidrológica em centros urbanos.

Inserido nesse contexto, o objetivo geral do presente estudo é avaliar a contribuição de coberturas verdes de acordo com a sua configuração (composição das camadas), na capacidade de retenção de água pluvial e no tratamento preliminar da água captada, de forma a verificar o potencial de aproveitamento dessa água para usos não potáveis em edifícios. Este artigo apresenta o aparato experimental desenhado, além das análises a serem desenvolvidas, uma vez que as células-teste encontram-se atualmente em fase de pré-teste na coleta de dados.

\subsection{Retenção e qualidade de água pluvial coletada em coberturas convencionais}

A água drenada pela cobertura pode ser aproveitada nos edifícios para usos não potáveis, tais como lavagem de pisos, descarga de bacias sanitárias e irrigação. Uma das principais preocupações quando se faz o aproveitamento de água pluvial, mesmo que para usos não potáveis, é a qualidade da água disponibilizada, de forma a não colocar em risco a saúde dos usuários.

A qualidade da água pluvial coletada é afetada por diferentes fatores (DESPINS;FARAHBAKHSH; LEIDL, 2009): as condições ambientais do entorno, tais como a proximidade de áreas industriais, grandes rodovias, presença de pássaros ou roedores; 
condições meteorológicas, tais como temperatura, períodos anteriores de seca e padrões de chuva; contato com o material de área de coleta e a sujeira e detritos que se depositam nesse local entre as chuvas; existência de tratamento antes e após a reservação da água pluvial, tais como filtração ou emprego de dispositivos de descarte da água de lavagem da cobertura, desinfecção por radiação ultravioleta, cloração, filtro lento de areia ou sistemas de água quente, e processos naturais de tratamento que ocorrem no interior do reservatório de água pluvial. O tipo de tratamento a ser conferido à água pluvial, portanto, depende das características da água coletada e do uso final não potável pretendido no edifício.

O estudo desenvolvido por Despins, Farahbakhsh e Leidl (2009) coletou amostras em sete diferentes cidades em um raio de $30 \mathrm{~km}$ da cidade de Guelph, Ontário, Canadá. Os resultados obtidos indicaram que os parâmetros físico-químicos da água pluvial sofreram modificações em função do material da cobertura, do material do reservatório e das condições ambientais do local em que o sistema se encontra. Com relação às condições ambientais, verificou-se que a estação do ano, a temperatura e o nível de tratamento empregado foram os fatores que mais influenciaram a qualidade microbiológica da água: durante o verão e outono, os coliformes fecais e totais foram detectados em um maior número de amostras.

\subsection{Retenção e qualidade de água pluvial coletada em coberturas verdes}

O potencial de coberturas verdes em reter a água pluvial é elevado se comparado a uma cobertura convencional. O escoamento para essas coberturas ocorre lentamente, dependendo das características do sistema e das propriedades dos materiais, tais como profundidade e composição do substrato, vegetação, drenagem e idade da cobertura (THOMPSON, 1998 apud BANTING et al., 2005). A capacidade de retenção da cobertura pode ser avaliada pelo coeficiente de descarte, ou seja, a relação entre os volumes de água precipitado e o volume drenado pela cobertura, que depende da profundidade do substrato (TAB. 1). 
TABELA 1 - Valores de referência: retenção de água pluvial de acordo com as características da cobertura verde.

\begin{tabular}{|c|c|c|c|c|}
\hline $\begin{array}{l}\text { Sistema de } \\
\text { cobertura } \\
\text { verde }\end{array}$ & $\begin{array}{l}\text { Profundidade } \\
\text { do substrato } \\
\text { (m) }\end{array}$ & Porte das plantas & $\begin{array}{l}\text { Retenção de } \\
\text { água - média } \\
\text { anual } \\
(\%)^{*}\end{array}$ & $\begin{array}{l}\text { Coeficiente anual } \\
\text { de descarte } \\
\Psi_{\text {a } / \text { coeficiente de }} \\
\text { selagem }{ }^{*}\end{array}$ \\
\hline Extensivo & $\begin{array}{l}0.02 \text { a } 0.04 \\
>0.04 \text { a } 0.60 \\
>0.06 \text { a } 0.10 \\
>0.10 \text { a } 0.15 \\
>0.15 \text { a } 0.20\end{array}$ & $\begin{array}{l}\text { Forrações e sedum } \\
\text { Sedum e forrações } \\
\text { Sedum, forrações e herbáceas } \\
\text { Sedum, herbáceas e forrações } \\
\text { Forrações e herbáceas }\end{array}$ & $\begin{array}{l}40 \\
45 \\
50 \\
55 \\
60\end{array}$ & $\begin{array}{l}0.60 \\
0.55 \\
0.50 \\
0.45 \\
0.40 \\
\end{array}$ \\
\hline Intensivo & $\begin{array}{l}0.15 \text { a } 0.25 \\
>0.25 \text { a } 0.50 \\
>0.50\end{array}$ & $\begin{array}{l}\text { Grama, arbustos e capão } \\
\text { Grama, arbustos e capão } \\
\text { Grama, arbustos, capão e } \\
\text { árvores }\end{array}$ & $\begin{array}{l}60 \\
70 \\
>90\end{array}$ & $\begin{array}{l}0.40 \\
0.30 \\
0.10\end{array}$ \\
\hline
\end{tabular}

* Os índices apresentados consideraram precipitações anuais entre $650 \mathrm{~mm}$ a $800 \mathrm{~mm}$. Para regiões com baixa precipitação anual, a retenção é maior.

Fonte: FLL, (2002).

VanWoert et al. (2005) avaliaram o impacto de coberturas na retenção de água pluvial a partir de uma pesquisa dividida em duas etapas. Na primeira delas, foram avaliadas três configurações de coberturas: com argila expandida, com cobertura verde e outra apenas com substrato. Para a coleta dos dados de descarte de água pluvial foram instaladas calhas com coletores individuais e pluviômetros de báscula, que registravam os dados a cada minuto. Dentre os resultados obtidos, destaca-se que, para uma chuva moderada $(2 \mathrm{~mm}-6 \mathrm{~mm})$, a cobertura com argila expandida é capaz de reter aproximadamente $50 \%$, enquanto a cobertura com vegetação retém mais de $80 \%$. Na segunda etapa, foram avaliadas coberturas verdes com diferentes declividades, sendo que a cobertura $0,04 \mathrm{~m}$ de substrato e inclinação de $2 \%$ reteve mais de $85 \%$.

Getter et al. (2007) utilizaram as células-teste elaboradas para a segunda fase do estudo desenvolvido por VanWoert et al. (2005), com alguns ajustes na inclinação das coberturas $(2,7,15$ e 25\%) e substrato com $0.06 \mathrm{~m}$. Para cada classificação registrou-se o número de vezes que cada tipo de precipitação ocorreu, identificando-os com a letra "n" (TAB. 2). 
TABELA 2 - Capacidade de retenção de água de chuva para diferentes inclinações de cobertura verde.

\begin{tabular}{lllll}
\hline \multirow{2}{*}{$\begin{array}{l}\text { Inclinação } \\
(\%)\end{array}$} & da cobertura & \multicolumn{4}{l}{ Capacidade de retenção (\%) } \\
\cline { 2 - 5 } & Leve & Moderada & Elevada & Média Total \\
\hline 2 & 93.3 & 92.2 & 71.4 & 85.2 \\
7 & 94.0 & 89.5 & 66.4 & 82.2 \\
15 & 94.0 & 88.6 & 58.4 & 78.0 \\
25 & 95.5 & 87.8 & 57.1 & 75.3 \\
Média & 94.2 & 89.5 & 63.3 & 80.2 \\
\hline Profundidade da camada de substrato - 6cm; precipitação leve $(<2 \mathrm{~mm})(\mathrm{n}=16) ;$ moderada $(2-10 \mathrm{~mm})$ \\
(n=24), elevado (>10mm) ( $\mathrm{n}=22)$ e total de eventos ( $\mathrm{n}=62)$. \\
\multicolumn{5}{c}{ Fonte: Getter et al. (2007). }
\end{tabular}

A pesquisa de Getter et al. (2007) foi realizada cinco anos após o primeiro estudo. Estes autores avaliaram também as propriedades físicas e orgânicas do substrato, sendo os resultados obtidos comparados com as amostras da primeira pesquisa, o que permitiu observar o desempenho do substrato com o passar dos anos. O substrato maturado (após cinco anos) potencializou as suas propriedades, elevando a sua capacidade na retenção de água pluvial, conforme apresentado na TAB. 3.

TABELA 3 - Matéria orgânica e propriedades físicas do substrato das coberturas verdes.

\begin{tabular}{lllll}
\hline Amostra & $\begin{array}{l}\text { Matéria } \\
\text { orgânica (\%) }\end{array}$ & $\begin{array}{l}\text { Porosidade } \\
(\%)\end{array}$ & $\begin{array}{l}\text { Espaço com } \\
(\%)\end{array}$ & $\begin{array}{l}\text { ar } \\
\text { Capacidade de controle } \\
\text { da água (\%) }\end{array}$ \\
\hline Substrato inicial & 2,33 & 41,41 & 21,43 & 17,07 \\
Substrato maturado & 4,25 & 81,84 & 14,40 & 67,44 \\
\hline
\end{tabular}
Fonte: Getter et al. (2007).

A qualidade da água pluvial drenada em coberturas verdes está diretamente relacionada às suas características, idade da cobertura, manutenção e fontes de poluição do local em que está inserida. Os cuidados com a manutenção devem ser observados, principalmente com a reposição de nutrientes (fertilizantes), considerado a principal fonte de contaminação da água por Fósforo (P), Fosfato (PO4) e Potássio (K) (TAB. 4), tornando-se fundamental o planejamento dessa etapa (EMILSSON et al., 2007).

Segundo Berndtsson et al. (2006) coberturas verdes reduzem a poluição da água pluvial, através da absorção de poluentes depositados na atmosfera, com exceção do Nitrogênio $(\mathrm{N})$, onde o nível de concentração depende das propriedades do substrato. Embora, concentrações de metais pesados sejam observadas, a qualidade global da água pluvial é considerada boa para fins não potáveis (TAB. 4). 
TABELA 4 - Concentração de nutrientes na água pluvial drenada por coberturas verdes (unidade: $\mathrm{mg} / \mathrm{L})$.

\begin{tabular}{|c|c|c|c|c|c|c|c|c|}
\hline Referência & Fonte & $\begin{array}{l}\text { Nitrogênio } \\
\text { Total } \\
\text { (N-tot) }\end{array}$ & $\begin{array}{l}\text { Nitrato de } \\
\text { nitrogênio } \\
\left(\mathrm{NO}_{3}-\mathrm{N}\right)\end{array}$ & $\begin{array}{l}\text { Nitrogênio } \\
\text { amoniacal } \\
\left(\mathrm{NH}_{4}-\mathrm{N}\right)\end{array}$ & $\begin{array}{l}\text { Potássio } \\
\text { (K) }\end{array}$ & $\begin{array}{l}\text { Fósforo } \\
\text { total } \\
(\text { Tot-P) }\end{array}$ & $\begin{array}{l}\text { Fosfato } \\
\text { Fosforoso } \\
\left(\mathrm{PO}_{4}-\mathrm{P}\right)\end{array}$ & $\begin{array}{l}\text { Ferro } \\
(\mathrm{Fe})\end{array}$ \\
\hline \multirow{2}{*}{$\begin{array}{l}\text { Teemusk e } \\
\text { Mander } \\
\text { (2007) }\end{array}$} & Precipitação & $0.6-1.3$ & $\begin{array}{l}0.18-0 . \\
09\end{array}$ & $\begin{array}{l}<0.015- \\
0.22\end{array}$ & \multirow{2}{*}{$\begin{array}{l}0.012- \\
0019 \\
0.026- \\
0.09\end{array}$} & 0.008 & \multirow{2}{*}{$\begin{array}{l}0.003- \\
0.004 \\
0.006- \\
0.066\end{array}$} & \multirow[b]{2}{*}{-} \\
\hline & $\begin{array}{l}\text { Água } \\
\text { drenada }\end{array}$ & $1.2-2.1$ & $0.42-0.8$ & $0.12-0.33$ & & 0.005 & & \\
\hline \multirow{2}{*}{$\begin{array}{l}\text { Berndtsson } \\
\text { et al., } \\
(2008)\end{array}$} & Precipitação & - & . & - & 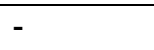 & - & . & - \\
\hline & $\begin{array}{l}\text { Extensivo } \\
\text { Intensivo }\end{array}$ & $\begin{array}{l}0.005 \\
0.01\end{array}$ & $\begin{array}{l}0.001 \\
0.02\end{array}$ & $\begin{array}{l}0.001 \\
0.05\end{array}$ & $\begin{array}{l}0.005 \\
0.1\end{array}$ & $\begin{array}{l}- \\
-\end{array}$ & $\begin{array}{l}0.001 \\
0.005\end{array}$ & $\begin{array}{l}0.001 \\
0.02\end{array}$ \\
\hline \multirow{2}{*}{$\begin{array}{l}\text { Berndtsson } \\
\text { et al., } \\
(2009)\end{array}$} & Precipitação & 2.65 & 1.03 & 1.08 & 0.04 & - & 0.02 & - \\
\hline & Extensivo & $\begin{array}{l}2.31 \\
0.59\end{array}$ & 0.07 & 0.08 & 0.31 & - & 0.27 & - \\
\hline
\end{tabular}

Para a análise do potencial de uma cobertura verde no que se refere à neutralização de chuvas ácidas, é importante avaliar periodicamente as propriedades do substrato, com 0 intuito de manter a estabilidade do $\mathrm{pH}$ e evitar a mortandade da vegetação. Segundo Berghage et al. (2007), uma cobertura verde perde a capacidade de neutralizar chuvas ácidas em dez anos, sendo necessário intervir após esse período.

Embora a água drenada em coberturas verdes seja considerada de boa qualidade, recomenda-se que estas não sejam indicadas como única ferramenta para o tratamento de água pluvial.

\section{Material e métodos}

O presente estudo contempla nove células-teste em escala real, com a aplicação de diferentes sistemas de coberturas verdes. As células-teste estão localizadas na cidade de Campinas, no interior do Estado de São Paulo, no campus da Faculdade de Engenharia Civil, Arquitetura e Urbanismo - FEC, na Universidade Estadual de Campinas - UNICAMP.

A partir da pesquisa experimental desenvolvida por VanWoert et. al (2005) e Getter et. al. (2007), as célula-teste foram instrumentadas com 8 pluviômetros de báscula (TE525MM da Campbell Scientific Inc.), que registrarão os dados de vazão de água pluvial das coberturas (a cada minuto), e um sensor de umidade (CS616 da Campbell Scientific Inc.), que verificará a porcentagem de saturação do substrato a cada 5 minutos, para que se possa avaliar a capacidade das coberturas verdes em reter água pluvial. Esses equipamentos estão conectados a multiplexadores e data loggers, que coletarão, registrarão e armazenarão os dados a cada 15 segundos, e a média após 1 hora, para que se possa avaliar a capacidade de retenção de água pluvial durante e após as precipitações (FIG. 2).

Tendo em vista os objetivos concomitantes da pesquisa como um todo (avaliação de desempenho térmico e capacidade de retenção e tratamento da água captada), o projeto de 


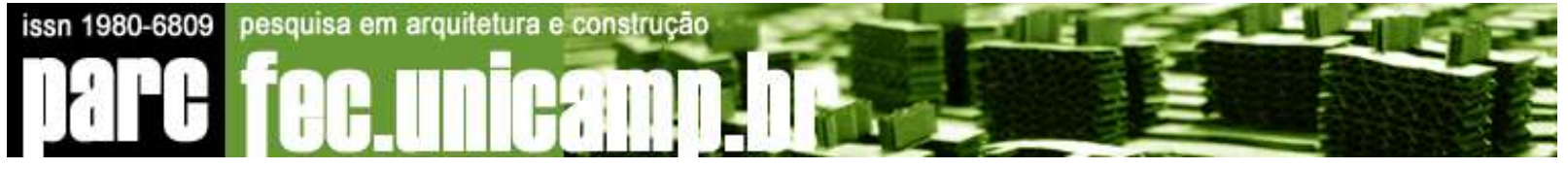

distribuição das células-teste foi elaborado de acordo com as condições climáticas locais e a posição do norte magnético, para maximizar a exposição das células-teste à radiação solar.

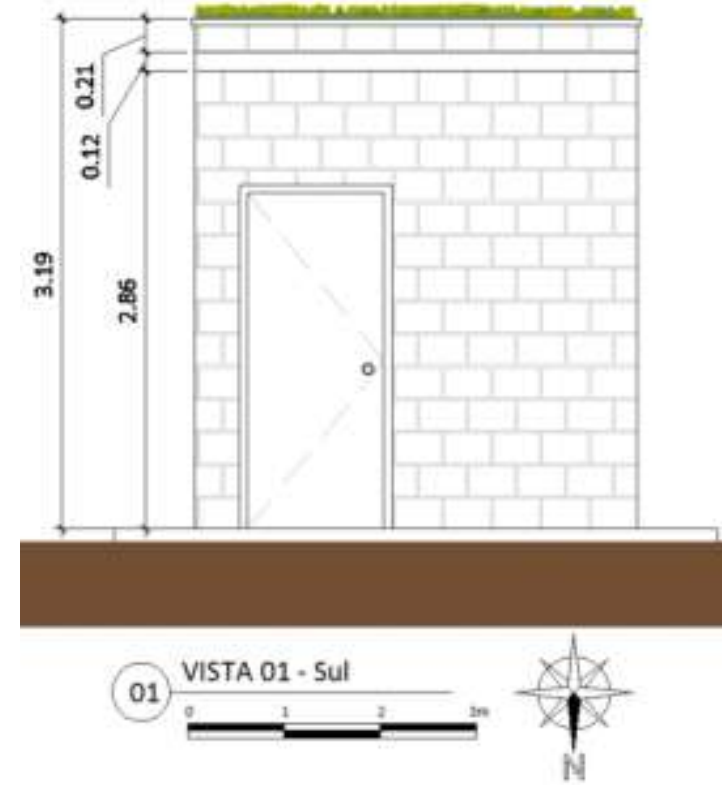

(a)

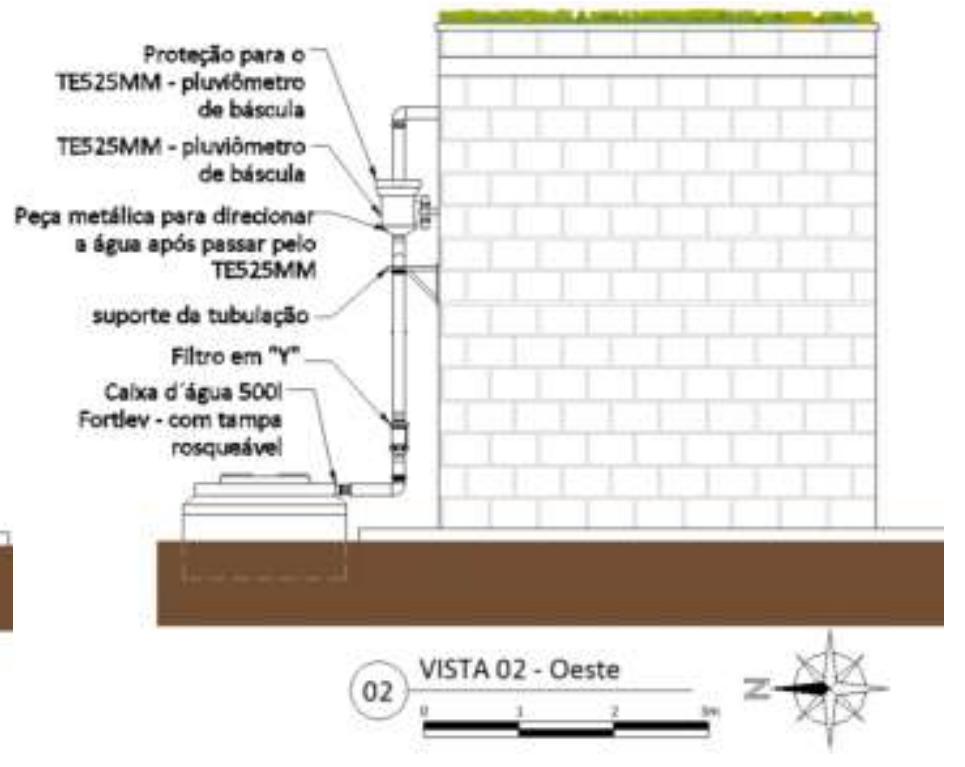

(b)

FIGURA 2 - (a) Vista 01 - Sul e (b) Vista 02 - Oeste.

Para o desenvolvimento da pesquisa, foram utilizados sistemas de coberturas verdes de dois fornecedores nacionais. Para auxiliar na composição, distribuição e identificação das células-teste, os sistemas foram identificados como Empresa 1 para as células $A, B, E, F, G$ e $\mathrm{H}$; Empresa 2, para as células C e D. Para a Empresa 1, aplicou-se sistema de cobertura verde do tipo extensivo, com $0,10 \mathrm{~m}$ de profundidade de substrato (células-teste $A, B, E$ e $F$ ), e semi-intensivo, com 0,25 m de profundidade de substrato (células-teste G e H) (FIG. 3). Para a Empresa 2, aplicou-se sistema de cobertura verde do tipo extensivo modular. Para a composição da camada com vegetação, especificaram-se as espécies de acordo com a classificação das coberturas e as condições climáticas locais. Para as células-teste $A, B$ e $C$ utilizou-se Zoyzia japônica; para a célula-teste D Sedum acre, para as células-teste E e F utilizou-se Aptenia cordifolia, Portulaca grandiflora, Echeveria Elegans e Lampranthus productus; para as células-teste $\mathrm{G}$ e $\mathrm{H}$ utilizaram-se apenas espécies tropicais brasileiras como Arachis repens, Evolvulos glomerantus e Lantana undulata. A célula-teste I configura uma cobertura convencional com telha cerâmica utilizada como referência. 

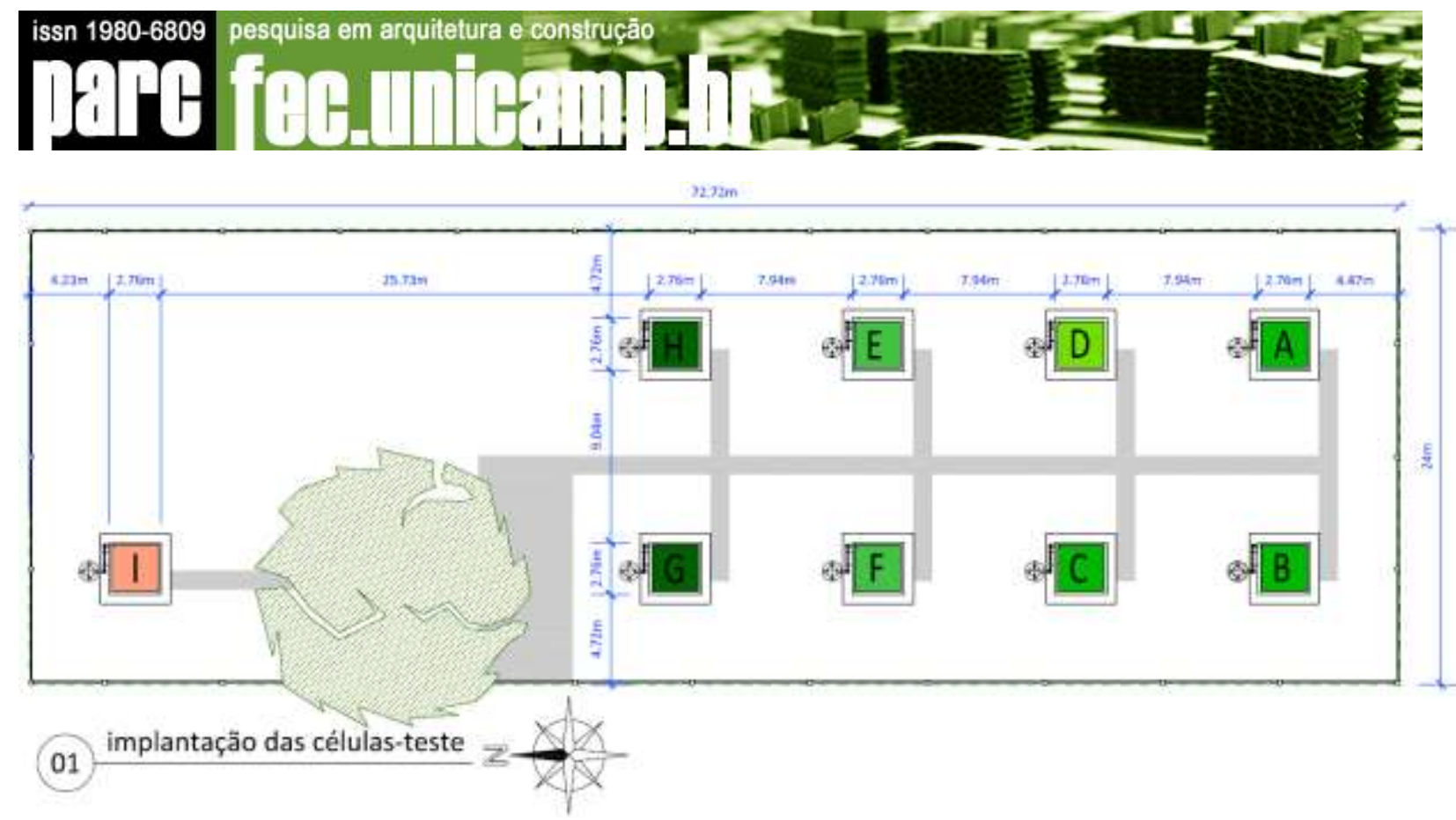

FIGURA 3 - Implantação das células-teste.

\subsection{Instrumentação}

As células-teste foram construídas sobre fundação radier de concreto desempenado $(3,56 \mathrm{~m} \times 3,56 \mathrm{~m})$, em alvenaria estrutural, laje pré-moldada, piso interno em cimento desempenado pintando com tinta para piso na cor cinza. As paredes externas e internas foram pintadas com tinta acrílica branca. Todas as coberturas receberam impermeabilizante do tipo manta asfáltica com proteção contra raízes, para evitar possíveis danos estruturais. As unidades possuem dimensões externas de $2,76 \mathrm{~m}^{\circ} \times 2,76 \mathrm{~m}, 2,8 \mathrm{~m}$ de pé direito, área de 7,62 m2 por célula-teste (FIG. 4). Para a drenagem a superfície das coberturas recebeu inclinação de $2 \%$, mínimo recomendado pela FLL (2002) para coberturas verdes.

Em paralelo, uma estação meteorológica foi instalada no local e será responsável pelos registros de temperatura e umidade relativa do ar, radiação solar, ventos e índices pluviométricos. A coleta de dados considerada terá duração mínima de 12 meses contínuos.

Logo após passar pelo pluviômetro de báscula, a água drenada das coberturas será distribuída entre cinco coletores. O restante da água drenada a coletar será direcionado para um filtro " $Y$ " e, por último, para o reservatório de 500 litros, do qual serão retiradas amostras para análise da água armazenada. 


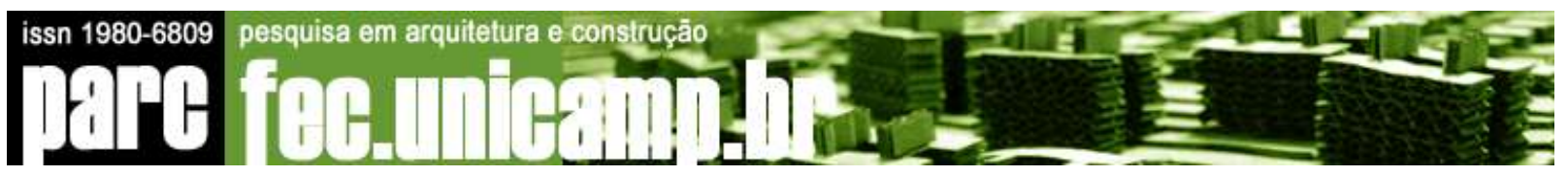

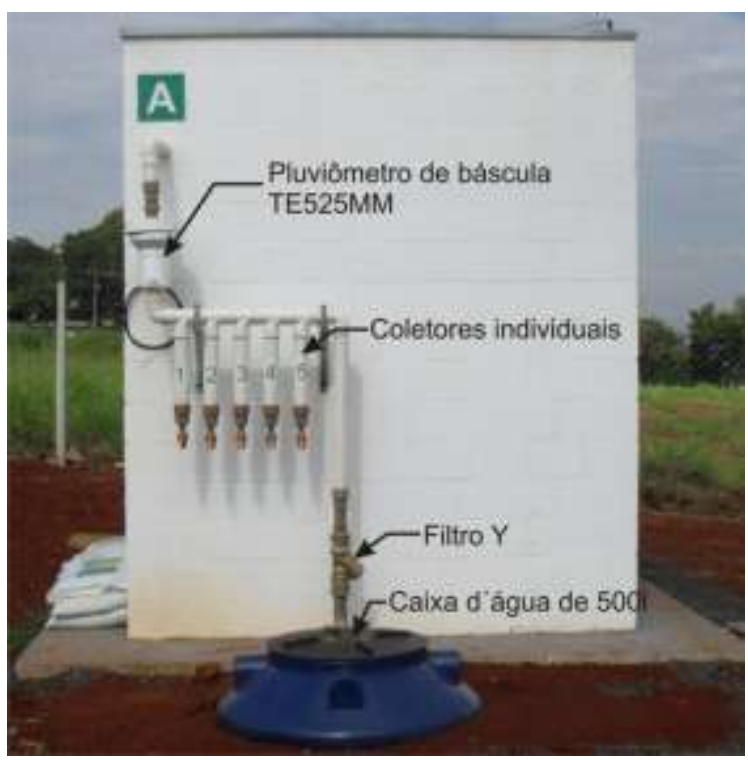

(a)

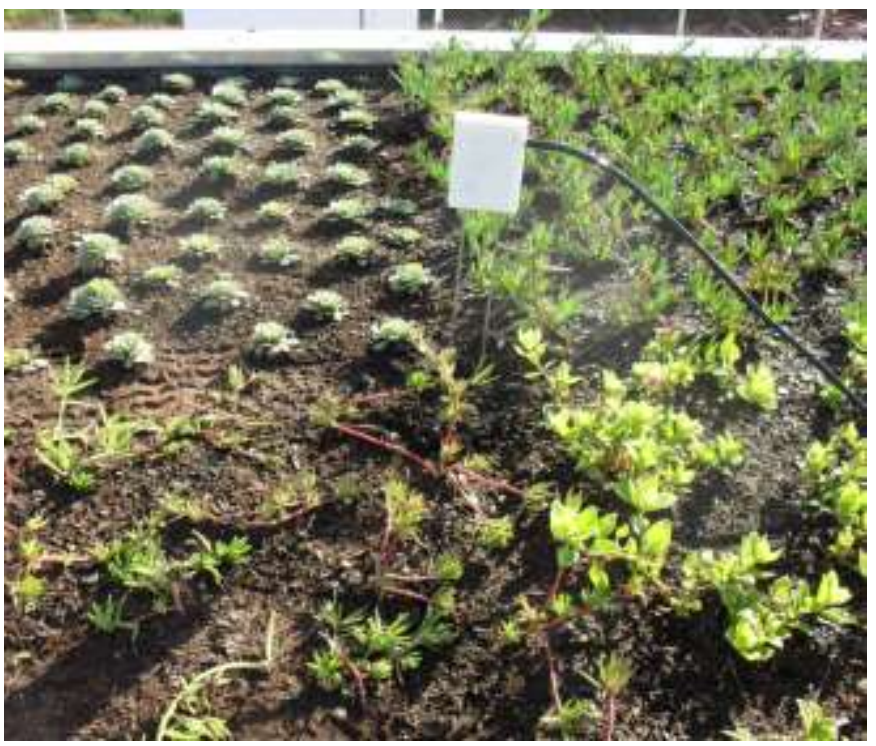

(b)

FIGURA 4 - (a) Aparato para análise de retenção e qualidade da água drenada e (b) Sensor de umidade CS616.

Com os dados registrados pelo pluviômetro de báscula, será possível aferir o coeficiente de selagem da camada vegetal (relação entre o volume de escoamento superficial e o volume de precipitação médio considerado para o local e tempo de duração) e estimar o potencial para diminuição da vazão no sistema de coleta pública de água pluvial, a partir da comparação entre a vazão de escoamento da água pluvial na célula-teste de referência (cobertura convencional) e as vazões medidas nas células-teste.

O potencial aproveitamento de água pluvial coletada depois de permear o sistema de cobertura será avaliado a partir dos resultados de parâmetros de qualidade da água das amostras coletadas, encaminhadas para testes no laboratório de saneamento da FEC/UNICAMP.

No tratamento dos dados, serão considerados a duração do evento, o volume da precipitação e o volume drenado registrado no equipamento, para estimar o quociente de retenção e de descarte de uma cobertura verde. A análise para o primeiro experimento será realizada individualmente para cada célula-teste, para que se possa utilizar os dados coletados para elaborar uma análise comparativa da capacidade de retenção das coberturas verdes de acordo com as diferentes configurações.

Após os eventos de precipitações, pretende-se coletar amostras da água escoada pelas coberturas e armazenada nos coletores individuais e no coletor único que coletará apenas a água de chuva. A coleta será feita em recipientes plásticos com capacidade de 1 litro 
(devidamente identificados), para verificar se existem variações na qualidade da água entre as diferentes configurações propostas nas dimensões para teste. Se possível, as análises para verificar a qualidade da água pluvial escoada pelas coberturas verdes serão comparadas com as amostras de uma cobertura em tamanho prevista com a construção de um laboratório na Faculdade de Engenharia Civil, Arquitetura e Urbanismo, Unicamp.

As amostragens determinarão os níveis de metais pesados, de matérias orgânicas e produtos químicos (por exemplo - fertilizantes), que indicarão o nível do pH da água. Além desses, serão avaliados todos os parâmetros de controle recomendados na NBR 15527 (ASSOCIAÇÃO BRASILEIRA DE NORMAS TÉCNICAS, 2007), quais sejam: cor aparente, turbidez, coliformes totais e termotolerantes.

\section{Considerações finais}

Nos últimos dez anos, houve um aumento significativo de pesquisas sobre coberturas verdes com o objetivo de determinar o potencial desse sistema na retenção de água pluvial, assim como na contribuição na mitigação dos danos causados por enchentes em áreas urbanas. A preocupação com o suprimento de água tem chamado à atenção da vanguarda internacional.

A tecnologia de coberturas verdes tem ganhado atenção da comunidade técnica devido ao seu potencial múltiplo em contribuir na mitigação dos danos causados pelas enchentes no meio urbano, em prover uma fonte de água alternativa, elevar a biodiversidade urbana e associada à economia de energia por melhoria de desempenho térmico nos ambientes interno e externo.

Uma pesquisa experimental em andamento na Universidade Estadual de Campinas pretende avaliar tanto o desempenho térmico como a contribuição na retenção de água pluvial em coberturas verdes implementadas em células-teste. Uma amostra significativa de sistemas de coberturas verdes presentes no mercado brasileiro, em diferentes configurações, profundidade do substrato e inclinação mínima de $2 \%$, permite quantificar o volume de água pluvial retida e parâmetros definidores da qualidade da água. O presente artigo descreve a abordagem proposta para dar suporte às avaliações.

A montagem experimental entrou em pré-teste em meados do mês de julho de 2010. 0 desdobramento da pesquisa inclui a análise comparativa de uma cobertura verde integral de um laboratório modelo a ser construído em 2011, para validar o modelo experimental em células-teste e/ou identificar eventuais limitações impostas quando se desenvolve estudos em células de tamanho limitado. 


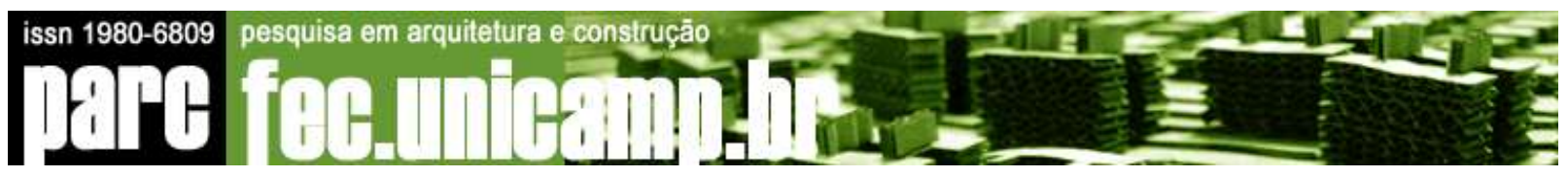

Baseando-se em dados climáticos da região de Campinas, São Paulo, espera-se determinar a contribuição do estudo com coberturas verdes na retenção de água pluvial e no pré-tratamento, assim como prover uma padronização de uma abordagem metodológica para replicar os estudos em outras regiões do Brasil.

\section{Agradecimentos}

À Fundação de Amparo à Pesquisa do Estado de São Paulo - FAPESP, pela concessão da bolsa de mestrado e auxílio regular à pesquisa, fundamentais para o desenvolvimento deste trabalho.

\section{Referências}

AGÊNCIA NACIONAL DE ÁGUAS. Conjuntura dos recursos hídricos no Brasil. Brasília, DF, 2009.

ASSOCIAÇÃO BRASILEIRA DE NORMAS TÉCNICAS. NBR 15527: Água de chuva Aproveitamento de coberturas em áreas urbanas para fins não potáveis - Requisitos. Rio de Janeiro, 2007.

BANTING, D. et al. Report on the Environmental Benefits and Costs of Green Roof Technology for the City of Toronto. Report. Department of Architectural Science, Ryerson University, Toronto, Ontario, Canada, 2005. p. 88. Disponível em: <http://www.toronto.ca/greenroofs/pdf/fullreport103105.pdf>. Acesso em: 29 ago. 2007.

BERGHAGE, R. et al. Quantifying evaporation and transpirational water losses from green roofs and green roof media capacity for neutralizing acid rain. Report. College of Agricultural Sciences, The Pennsylvania State University, North Carolina State University, University Park, Pennsylvania, United State of America, 2007. p. 94. Disponível em: <http://www.ndwrcdp.org/userfiles/04-DEC-10SG.pdf>. Acesso em: 21 jul. 2008.

BERNDTSSON, J. C.; BENGTSSON, L.; JINNO, K. Runoff water quality from intensive and extensive vegetated roofs. Ecological Engineering, v.In Press, Corrected Proof, p.1-12. 2008. Disponível em: <http://www.sciencedirect.com/science/article/B6VFB-4V2X6MD1/2/c51dc4452743afcfa8f3f057195c3cbe>. Acesso em: 8 dez. 2008.

BERNDTSSON, J. C.; BENGTSSON, L.; JINNO, K. Runoff water quality from intensive and extensive vegetated roofs. Ecological Engineering, v.35, n.3, p.369-380. 2009. Disponível em: <http://www.sciencedirect.com/science/article/B6VFB-4V2X6MD1/2/c51dc4452743afcfa8f3f057195c3cbe>. Acesso em: 29 mar. 2009. 
BERNDTSSON, J. C.; EMILSSON, T.; BENGTSSON, L. The influence of extensive vegetated roofs on runoff water quality. Science of The Total Environment, v.355, n.1-3, p.48-63. 2006. Disponível em: <http://www.sciencedirect.com/science/article/B6V78-4FY9M7H4/2/eaadbbca7c77f7e45f301ca86a6a6caf>. Acesso em: 8 dez. 2008.

CANTOR, S. L. Green roofs in sustainable landscape design. New York, NY: W.W. Norton \& Company. 2008. p. 352.

CARTER, T.; JACKSON, C. R. Vegetated roofs for stormwater management at multiple spatial scales. Landscape and Urban Planning, v.80, n.1-2, p.84-94. 2007. Disponível

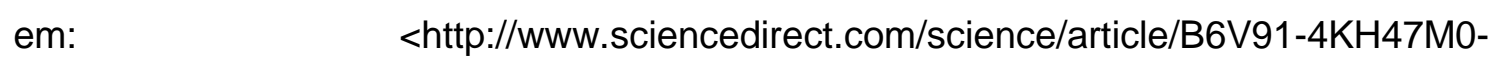
1/2/09427735b51e6e8813bfd2000caf71b3 >. Acesso em: 29 ago. 2007.

DESPINS, C.; FARAHBAKHSH, K.; LEIDL, C. Assessment of rainwater quality from rainwater harvesting systems in Ontario, Canada. Journal of Water Supply: Research and Technology - AQUA. 2009.

EMILSSON, T. et al. Effect of using conventional and controlled release fertiliser on nutrient runoff from various vegetated roof systems. Ecological Engineering, v.29, n.3, p.260271. 2007. Disponível em: <http://www.sciencedirect.com/science/article/B6VFB4MY0TT4-1/2/36ce2b751c8fb383761c54df1f767ca1 >. Acesso em: 17 dez. 2008.

FORSCHUNGSGESELLSCHAFT LANDSCHAFTSENTWICKLUNG LANDSCHAFTSBAU E.V. Guideline for the planning, execution and upkeep of green-roof sites: roofgreening guideline. Germany: Forschungsgesellschaft Landschaftsentwicklung Landschaftsbau e.V. 2002. p. 95.

GETTER, K. L.; ROWE, D. B.; ANDRESEN, J. A. Quantifying the effect of slope on extensive green roof stormwater retention. Ecological Engineering, v.31, n.4, p.225-231. 2007. Disponível em: <http://www.sciencedirect.com/science/article/B6VFB-4PRHKTG1/2/2d8052a706781b398dd98c2898a51a6f >. Acesso em: 17 dez. 2008.

NUNES, S. S. Estudo da conservação de água em edifícios localizados no campus da Universidade Estadual de Campinas. Dissertação (mestrado). Faculdade de Engenharia Civil, Universidade Estadual de Campinas, Campinas, SP, 2000.

OLIVEIRA, L. H. The influence of water losses in the water consumption indicator value of apartment buildings. Conference Proceedings. 27th International Symposium CIB W62, 2001. Portoroz, Slovenia. 2001. 


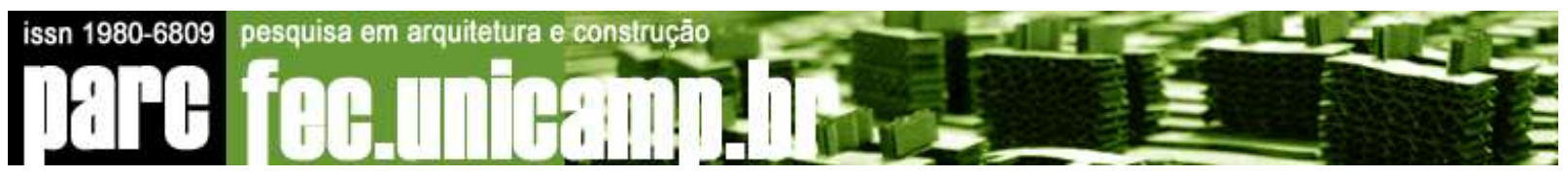

SAUTCHUK, C. Formulação de diretrizes para a implantação de programas de conservação de água em edificações. Escola Politécnica da Universidade de São Paulo, São Paulo, 2004.

TEEMUSK, A.; MANDER, Ü. Rainwater runoff quantity and quality performance from a greenroof: The effects of short-term events. Ecological Engineering, v.30, n.3, p.271277. 2007. Disponível em: <http://www.sciencedirect.com/science/article/B6VFB4N6NHG4-1/2/5ae5bd3f9a1a1aef463f16f80c757ffe>. Acesso em: 10 dez. 2008.

U.S. ENVIRONMENTAL PROTECTION AGENCY. Low-Impact development: an design strategies an Integrated design approach. Maryland, p. 150, 1999. Disponível: <http://www.epa.gov/owow/nps/lid/lidnatl.pdf>. Acesso em: 22 jan. 2009.

VANWOERT, N. D. et al. Green Roof Stormwater Retention: Effects of Roof Surface, Slope, and Media Depth. J Environ Qual, v.34, n.3, May 11, 2005, p.1036-1044. 2005. Disponível em: <http://jeq.scijournals.org/cgi/content/abstract/joenq;34/3/1036>. Acesso em: 10 dez. 2008.

WATER BY DESIGN. Concept Design Guidelines for Water Sensitive Urban Design. 2009. Disponível em: <http://waterbydesign.com.au/>. Acesso em: 06 jun. 2010. 